\title{
Yet another risk factor appears
}

\author{
Erin E. Gordon, DO, ${ }^{a}$ and R. D. B. Jaquiss, MD $^{\mathrm{b}}$
}

\footnotetext{
From the Departments of ${ }^{\mathrm{a}}$ Pediatrics and ${ }^{\mathrm{b}}$ Thoracic and Cardiovascular Surgery, UT Southwestern Medical Center and Children's Medical Center, Dallas, Tex.

Disclosures: Authors have nothing to disclose with regard to commercial support.

Received for publication Aug 26, 2017; accepted for publication Aug 30, 2017; available ahead of print Oct 3, 2017.

Address for reprints: R. D. B. Jaquiss, MD, Department of Thoracic and Cardiovascular Surgery, UT Southwestern Medical Center and Children's Medical Center, 1935 Medical District Dr, Dallas, TX 75235 (E-mail: Robert.jaquiss@utsouthwestern.edu).

J Thorac Cardiovasc Surg 2018;155:1148-9

0022-5223/\$36.00

Copyright $(\underset{0}{ } 2017$ by The American Association for Thoracic Surgery

http://dx.doi.org/10.1016/j.jtcvs.2017.08.105
}

Although survival for neonates, children, and adolescents undergoing surgery for congenital heart disease has increased dramatically due to medical and surgical advancements, such patients remain at risk for neurodevelopmental impairment, with a significant unexplained individual variability in early and late neurologic outcomes. ${ }^{1}$ Investigators have examined the associations of poor neurologic outcomes with potential risk factors such as type of congenital heart disease, degree of cyanosis, timing of surgery, anesthetic exposures (ie, number of cardiac and noncardiac surgical procedures), parental education and socioeconomic status, biomarkers, and pre- and postoperative management. The present work by Kim and colleagues ${ }^{2}$ explores a new type of potential risk factor for adverse neurologic outcomes: A genetic variation in the innate immune system. The authors retrospectively analyzed a cohort of nonsyndromic infants with congenital heart disease, comparing neurodevelopmental outcomes in those with the missense mutation in the MBL2 gene resulting in mannose-binding lectin (MBL) deficiency to outcomes in those with normal MBL levels. At age 4 years, neurodevelopmental status was assessed in 3 domains: full-scale intellectual quotient, visual motor integration, and using the Child Behavior Checklist. A statistically significant association between the MBL-deficient genotype group and pervasive developmental problems was found $(P=.0025)$. Additionally, this association was amplified in those children requiring surgical interventional earlier in life $(P=.039)$.

The findings are consistent with other studies in juvenile and pediatric subjects that demonstrate that MBL deficiency is associated with worse neurologic outcomes, ${ }^{3-5}$ although an opposite effect has been reported in mature subjects. 6,7 This paradox of apparently contradictory implications of MBL deficiency, with outcomes that are better or worse depending on age, is mirrored in the present study wherein the MBL-deficient cohort had worse neurologic outcomes but shorter (ie, better) length of hospital stay. Although this was not a primary focus of study and the outcome is a so-called soft outcome, the finding suggests a more salutary early postsurgical course for MBL-deficient patients.

\section{References}

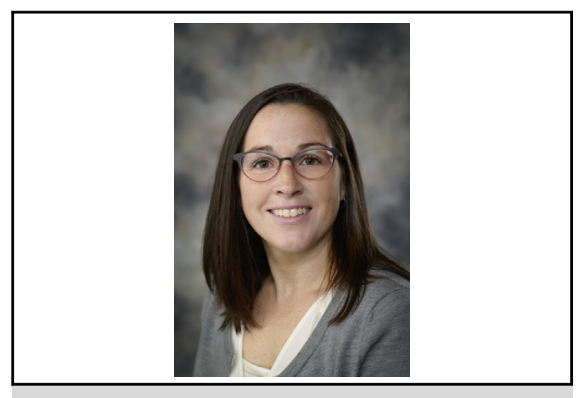

Erin E. Gordon, DO

\section{Central Message}

Deficiency of mannose binding lectin is associated with worse neurodevelopmental outcomes after congenital heart surgery through an unknown mechanism, with exaggerated effect in the youngest patients.

See Article page 1139 .

Based on the known association between MBL deficiency and infections in children, ${ }^{8,9}$ the authors ${ }^{2}$ speculate that the mechanism of neurologic insult is infectious, but do not offer data about the number, type, or severity of infections in the cohorts. An intriguing alternative explanation is that late neurodevelopmental deficit in MBLdeficient patients relates not to infection, but rather to a maladaptive inflammatory response. There is accumulating evidence suggestive of a role of the immune system, specifically deficiency in the complement pathway, in the pathophysiology of autism spectrum disorders. ${ }^{10}$ Perhaps the MBL-deficient patients simply had a predisposition to pervasive developmental problems.

Although a mechanistic explanation for the novel observations by $\mathrm{Kim}$ and colleagues ${ }^{2}$ remains obscure, they have presented yet another risk factor to be considered when counseling parents of children with congenital heart disease. Furthermore, their findings of worse outcomes in MBL-deficient patients undergoing surgery at the youngest age certainly requires further study. In contrast to genetic predisposition, type of heart condition, and age and weight at birth, the choice of surgical timing is perhaps the only variable over which a care team may have some influence.

1. Marino BS, Lipkin PH, Newburger JW, Peacock G, Gerdes M, Gaynor JW, et al. Neurodevelopmental outcomes in children with congenital heart disease: evaluation and management: a scientific statement from the American Heart Association. Circulation. 2012;126:1143-72. 
2. Kim DS, Li YK, Kim JH, Bergquist C, Gerdes M, Bernbaum JC, et al. Autosomal dominant mannose-binding lectin deficiency is associated with worse neurodevelopmental outcomes after cardiac surgery in infants. J Thorac Cardiovasc Surg. 2018;155:1139-47.

3. Koroglu OA, Onay H, Erdemir G, Yalaz M, Cakmak B, Akisu M, et al. Mannosebinding lectin gene polymorphism and early neonatal outcome in preterm infants. Neonatology. 2010;98:305-12.

4. Auriti C, Prencipe G, Caravale B, Coletti MF, Ronchetti MP, Piersigilli F, et al. $M B L 2$ gene polymorphisms increase the risk of adverse neurological outcome in preterm infants: a preliminary prospective study. Pediatr Res. 2014;76:464-9.

5. Yager PH, You Z, Qin T, Kim HH, Takahashi K, Ezekowitz AB, et al. Mannose binding lectin gene deficiency increases susceptibility to traumatic brain injury in mice. J Cereb Blood Flow Metab. 2008;28:1030-9.

6. Longhi L, Orsini F, De Blasio D, Fumagalli S, Ortolano F, Locatelli M, et al. Mannose-binding lectin is expressed after clinical and experimental traumatic brain injury and its deletion is protective. Crit Care Med. 2014;42: 1910-8.

7. Cervera A, Planas AM, Justicia C, Urra X, Jensenius JC, Torres F, et al. Geneticallydefined deficiency of mannose-binding lectin is associated with protection after experimental stroke in mice and outcome in human stroke. PLoS One. 2010; 5:e8433.

8. Pradhan V, Gorakshakar A. Are mannose binding lectin gene 2 (MBL2) polymorphisms and MBL deficiency associated with infections? Indian J Hum Genet. 2011;17:45-7.

9. Bouwer MC, Baas F, Van der Ende A, Van de Beck D. Genetic variation and cerebrovascular fluid levels of mannose binding lectin in pneumococcal meningitis patients. PLoS One. 2013;8:e65151.

10. Fagan K, Crider A, Ahmed AO, Pillai A. Complement C3 expression is decreased in autism spectrum disorder subjects and contributes to behavioral defects in rodents. Mol Neuropsychiatry. 2017;3:19-27. 